\title{
STUDY ON THE EFFECT OF VISCOUS DAMPER FOR RCC FRAME STRUCTURE
}

\author{
Puneeth Sajjan $^{1}$, Praveen Biradar ${ }^{2}$ \\ ${ }^{I}$ Student, Department of Civil Engineering, BLDE CET, Vijaypur, Karnataka, India \\ ${ }^{2}$ Assistant Professor, Department of Civil Engineering, BLDE CET, Vijaypur, Karnataka, India
}

\begin{abstract}
Structures are mainly subjected to various types of loading conditions such as earthquake, wind loads etc. For earthquake zone areas, the structures are designed considering seismic forces. The structure which are present in higher earthquake zone area are liable to get damaged or collapsed, hence to increase the safety of these structure few retrofitting techniques or addition of materials to stabilize the structures against the earthquake forces are done. And if the retrofitting techniques are adopted then cost plays an important role and possibly few spaces will be compromised depend upon the type of methods adopted. Later the structure may be strengthened by adding materials externally to transfer the lateral loads i.e. some protective devices have been developed. In modern seismic design, damping devices are used to reduce the seismic energy and enable the control of the structural response of the structure to that learthquake excitation. For the present study, an 8-story structure which is symmetrical in plan is modelled and analyzed using the ETABs 2015 software. The earthquake loads are defined as per IS1893-2002 (Part 1). To analyze the structure, the static and dynamic analysis method is adopted. The response spectrum function is defined to carry out dynamic analysis. To control the seismic response and to increase the stiffness of the structure, viscous damper are provided to the structure. The structure with viscous damper is modelled and analyzed with same parameters. The mechanical properties of viscous damper used in this study are as damping coefficient $C d=810 \mathrm{kN}-\mathrm{s} / \mathrm{m}$ and exponent as 0.3. The results obtained and compared in the form of displacement, story drift and story shear are compared.
\end{abstract}

Keywords: Structures, Dynamic Analysis, Seismic Response, Earthquake, Viscous Damper. ****

\section{INTRODUCTION}

From the past and few present records, the world has experienced number of destroying earthquakes, causing in number of increase the loss of human being due to structural collapse and severe damages to structure. Because of such type of structural damages, during seismic (earthquake) hazards clearly explains that the buildings / structures like residential buildings, public life-line structures, historical structures and industrial structures should be designed to seismic force design and very carefully to overcome from the earthquake hazards. The approach in structural design using seismic response control device is now widely accepted for structure and frequently used in civil engineering field. Serious efforts have been undertaken to develop the structural control concept into a workable technology and such devices are installed in structures.

The structural control system is usually classified by three methods. The three classes of structural control system are active energy dissipation, semi-active and passive energy dissipation. The passive energy systems are devices which are used to dissipate the seismic effect. The main function of the passive devices is to absorb a part of earthquake energy i.e., input energy, reducing earthquake energy or force on structural members and to reducing the percentage of the damage to the structures. Comparing to semi-active or active systems there is no need of external power supply to passive control system. The active control system is controllable and requires some amount of external supply in processing. The active control system will operate on the sensor which is attached to structure. The semi-active systems are the energy dissipating devices which is the combination of both active and passive control system.

Table 1: Material Properties

\begin{tabular}{|l|l|}
\hline Beam & $230 \mathrm{~mm} \mathrm{X} \mathrm{450mm}$ \\
\hline Column & $500 \mathrm{~mm}$ X 500mm \\
\hline Slab Thickness & $150 \mathrm{~mm}$ \\
\hline \multirow{2}{*}{ Wall thickness } & $230 \mathrm{~mm}$ \\
\cline { 2 - 2 } & $150 \mathrm{~mm}$ \\
\hline Grade of concrete & $\mathrm{M} 25$ \\
\hline Grade of Steel & $\mathrm{Fe}-415$ \\
\hline Poisson ratio & 0.2 \\
\hline
\end{tabular}

\section{DAMPERS}

Dampers are the devices which are used to absorb or dissipate the vibration caused by the earthquake to the structure and to increase the damping and stiffness of the structure.
Types of Damper
1. Tuned mass damper (TMDs).
2. Tuned liquid mass damper (TLDs).
3. Friction damper
4. Metallic damper.
5. Viscous damper.
6. Elasto plastic damper. 


\section{ABOUT THE VISCOUS DAMPER}

The Viscous dampers are passive energy dissipation device which is added to structure to increase the effective stiffness of new and existing buildings. They are very robust material and energy is transferred by piston and absorbed or vanishes by silicone-based fluid flowing between the piston-cylinder arrangement [8].The damping force of viscous damper is given by[2]

$\mathrm{F}=\mathrm{CV} \alpha$

where,

$\mathrm{F}$ - The damping force.

C - The damping coefficient.

V - Velocity of Piston.

$\alpha-$ Velocity Exponent.
The viscous damper works on the principle of flow of fluid through the orifice in the chamber. The silicone-based fluid is used in the chamber. The piston which is made up of stainless steel travels in the chamber which is filled by the silicone oil. The characteristic of the silicone oil is inert, non-flammable, nontoxic and extremely stable for a period of long time. The pressure or force developed by the earthquake will be of different. This difference in pressure between two chambers will force the oil to flow through orifice in piston head. The inside energy is transferred into heat which will dissipate into the atmosphere. These dampers can be operated in the temperature fluctuation of about $-40^{\circ} \mathrm{C}$ to $+60^{\circ} \mathrm{C}$. Due to easy $\mathrm{n}$ installation, adaptable and having variety in their sizes, these dampers have more application in designing and retrofitting of the structure.

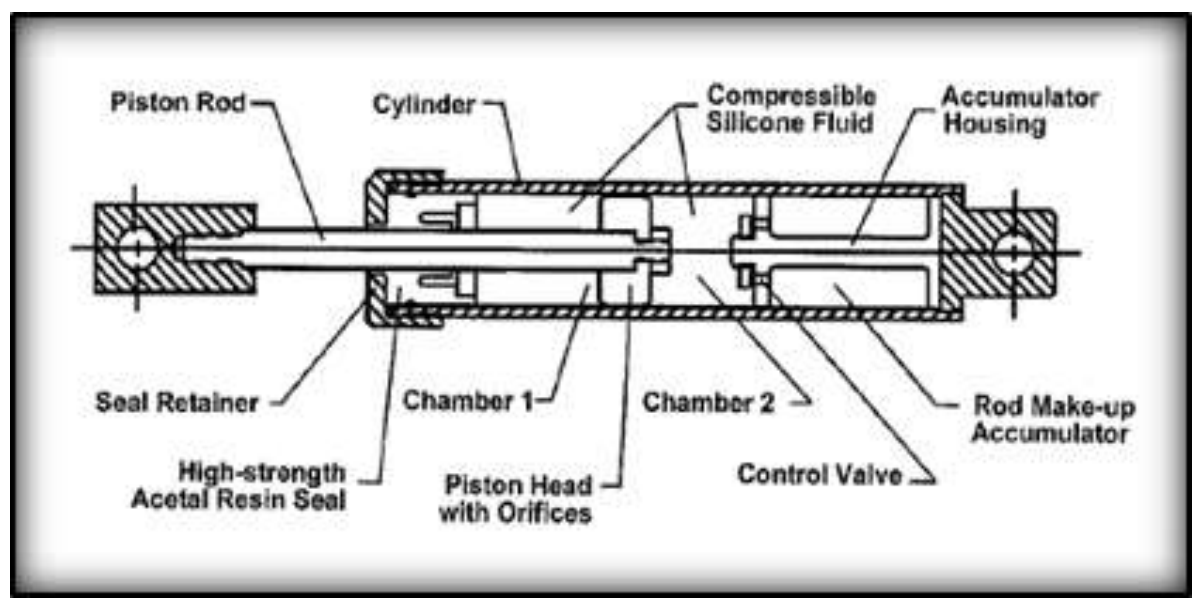

Fig 1: Detail of Viscous Damper [7]

Basic Way of Applying Damper

The three basic ways to apply the damper to the structure:

1. Base isolation.

2. Damper for chevron bracing system.

3. Damper for diagonal bracing system.

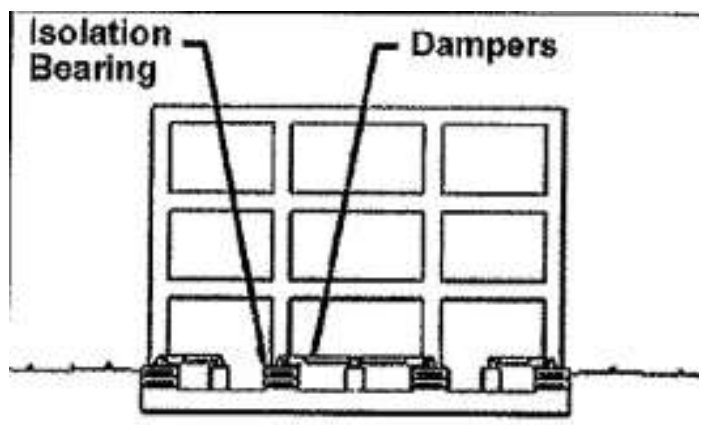

DAMPERS WITH BASE ISOLATION

Fig 2: Damper with Base Isolation [7]

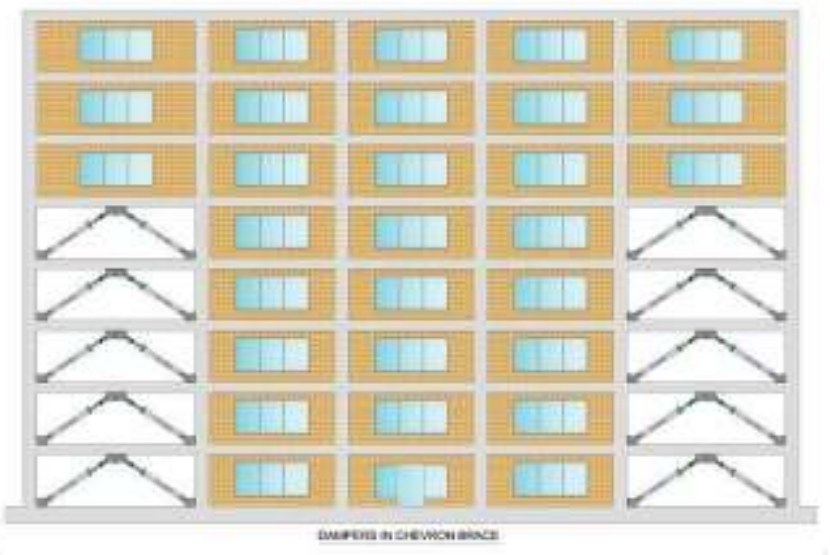

Fig 3: Damper in Chevron Brace [9] 


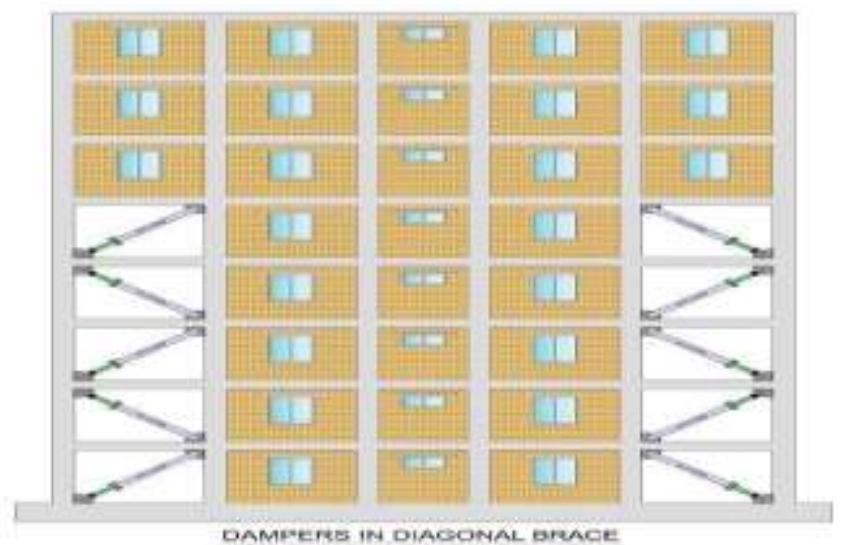

Fig 4: Dampers in Diagonal Brace [9]

\section{LOAD CONSIDERATION}

Structural details considered for the analysis dead load of $1.5 \mathrm{kN} / \mathrm{m}^{2}$, live load of $3 \mathrm{kN} / \mathrm{m}^{2}$ as per IS 875 -part II, finishing of $1.5 \mathrm{kN} / \mathrm{m}^{2}$ and wall load for $230 \mathrm{~mm}$ thick, load is $12 \mathrm{kN} / \mathrm{m}$ and for $150 \mathrm{~mm}$ thick, load is $7.8 \mathrm{kN} / \mathrm{m}$. Earthquake loads as per IS-1893:2002(Part-I).

\section{APPLICATION OF VISCOUS DAMPER AND ITS PROPERTIES}

Damper is a device which is applied to the structure to reduce the seismic effect of the structure. In ETABs the viscous damper element is assigned to the structure in the form of chevron bracing throughout the height of the structure at all corners of the structure. A panel zone is defined at the midpoint of the beam with non-linear link property. The chevron will intersect to the mid-point of the beam where the panel zone is assigned. In the panel zone, the beam-brace connectivity is selected with non-linear behaviour in $\mathrm{U} 2$ direction for assigning the damper.

The properties of the Viscous Damper are considered as provided by the manufacturing company Taylor Device Inc.,

Damping coefficient: $810 \mathrm{kN}-\mathrm{s} / \mathrm{m}$

Velocity exponent: 0.3

The stiffness value of the viscous damper is calculated by the following formula by considering the force and displacement of the bare structure.

Force $=$ Stiffness $*$ Displacement i.e., $\mathrm{F}=\mathrm{K} * \delta$

$\mathrm{K}=5,95,238.0953 \mathrm{kN} / \mathrm{m}$

\section{ETAB MODEL}

The structure of 8-story is considered which is of reinforced concert structure. The plan of the structure is symmetric plan, having the area of $20 \mathrm{~m} \times 20 \mathrm{~m}$. Each spacing of the gridline is $5 \mathrm{~m}$ on both side. The height of each story of the structure is $3 \mathrm{~m}$. The overall height of the structure is $24 \mathrm{~m}$. The frame of the structure is modelled in ETABs software.

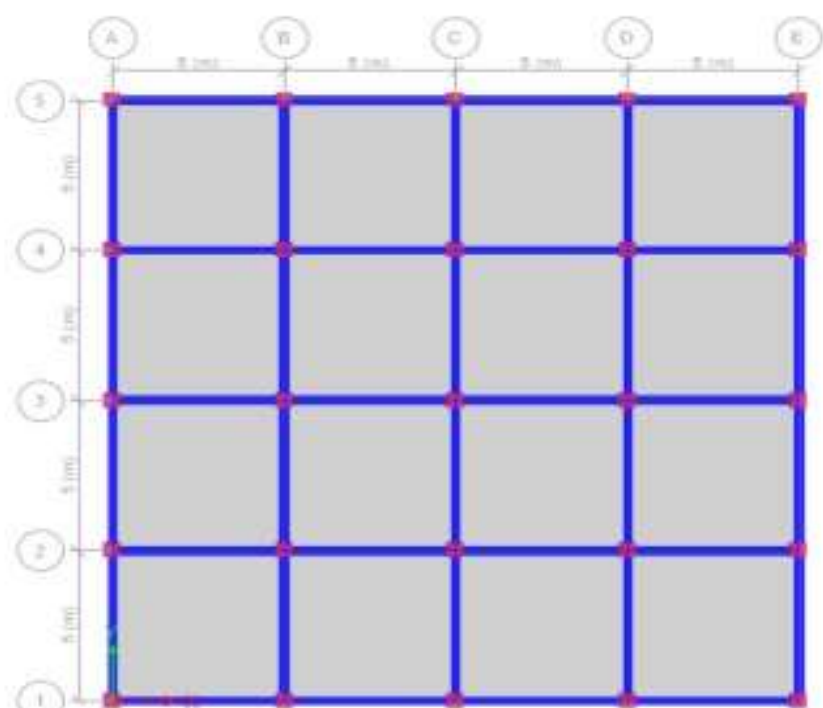

Fig 5: Plan of the Model

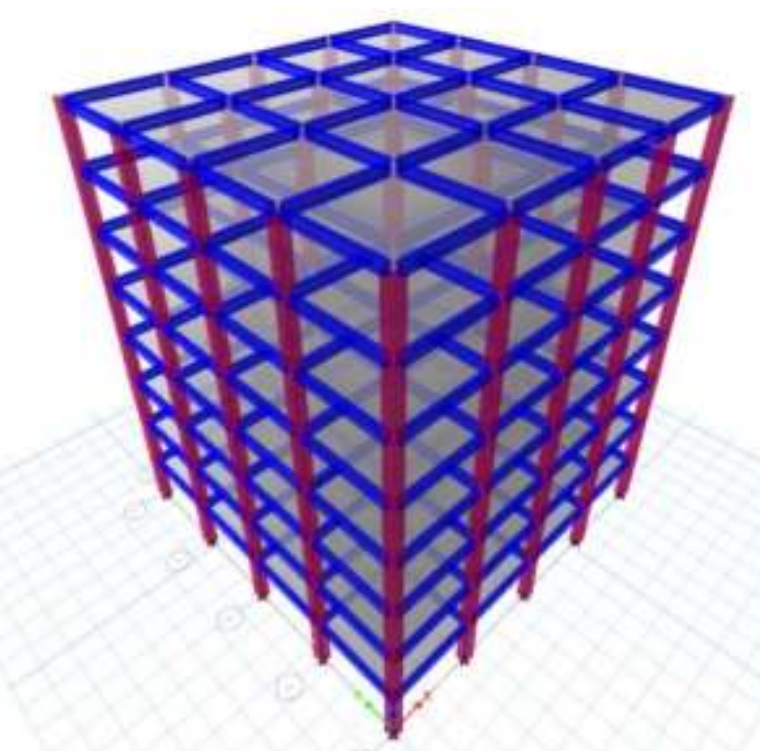

Fig 6: 3D View ofthe Model

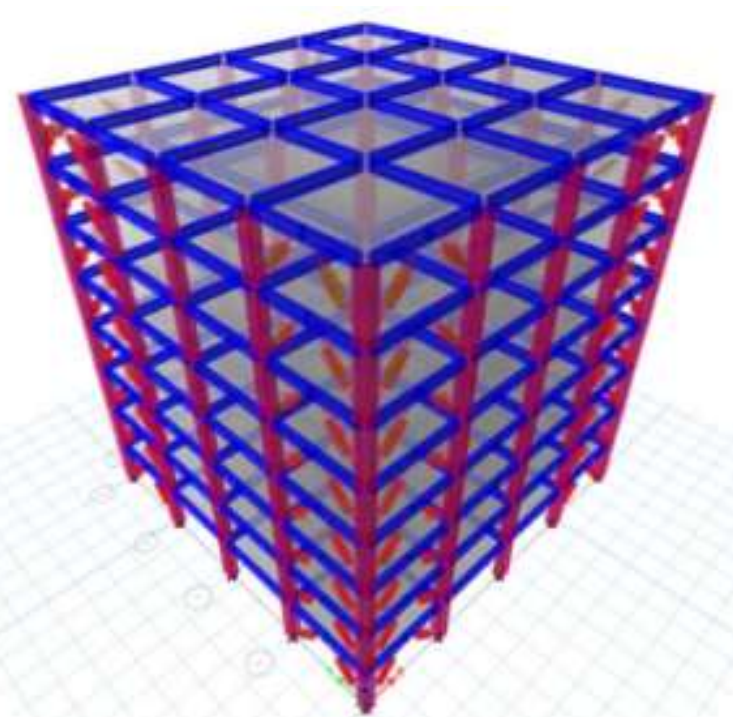

Fig 7: 3D view of Model with Viscous Damper 


\section{ANALYSIS}

In this present study, the ETABs 2015 software is used for modelling as well as analysis of the structure. The symmetrical plan of reinforced concrete structure having 8story is considered. The structure without damper is modelled and analyzed in ETABs 2015. The model is assigned the class of gravity loads. First the Earthquake loads as per IS1893-2002, Part-1 is applied for structure located in zone 3. And dynamic analyses i.e. Response spectrum method is carried out for 5\% damping and scale factor considered as per IS code in both $\mathrm{X}$ and $\mathrm{Y}$ directions. To control the seismic response of the structure and to absorb or to transfer the lateral loads of the structure, the viscous damper is provided. The viscous damper is modelled in the ETABs software.

\section{DISCUSSIONS AND RESULTS}

In the present study, viscous dampers are used to reduce the seismic effect of the structure which are subjected to the earthquake load. The frames (with and without viscous damper) is modelled according to the properties of the structure which are explained in the work. The models are subjected to analyse for gravity load (i.e., dead and live load) and seismic loads. Dynamic analysis is carried out by response spectrum method according to the Indian Standards codes by using ETABs 2015 software. Because of the symmetric model the values in both direction will be same. The seismic behaviour of the Reinforced Concrete structure is judged by observing the parameters such as displacement, story drift and story shear.

\subsection{Displacement}

Displacement is the parameter of maximum importance as it governs the failure pattern of the structure. From this present study, the displacement of the model with and without viscous damper are observed.By providing the damper to the structure we observe that the displacement of the structure is reduced.

Table 2: Displacement (mm)

\begin{tabular}{|l|l|l|l|}
\hline \multirow{2}{*}{ Story } & \multirow{2}{*}{$\begin{array}{l}\text { Elevation } \\
(\mathbf{m})\end{array}$} & \multicolumn{2}{|c|}{ Displacement (mm) } \\
\cline { 3 - 4 } & & $\begin{array}{l}\text { without } \\
\text { damper }\end{array}$ & $\begin{array}{l}\text { with } \\
\text { viscous } \\
\text { damper }\end{array}$ \\
\hline 8 & 24 & 29.63 & 10.73 \\
\hline 7 & 21 & 28.22 & 9.70 \\
\hline 6 & 18 & 25.87 & 8.39 \\
\hline 5 & 15 & 22.57 & 6.87 \\
\hline 4 & 12 & 18.42 & 5.22 \\
\hline 3 & 9 & 13.53 & 3.52 \\
\hline 2 & 6 & 8.14 & 1.86 \\
\hline 1 & 3 & 2.92 & 0.46 \\
\hline Base & 0 & 0 & 0 \\
\hline
\end{tabular}

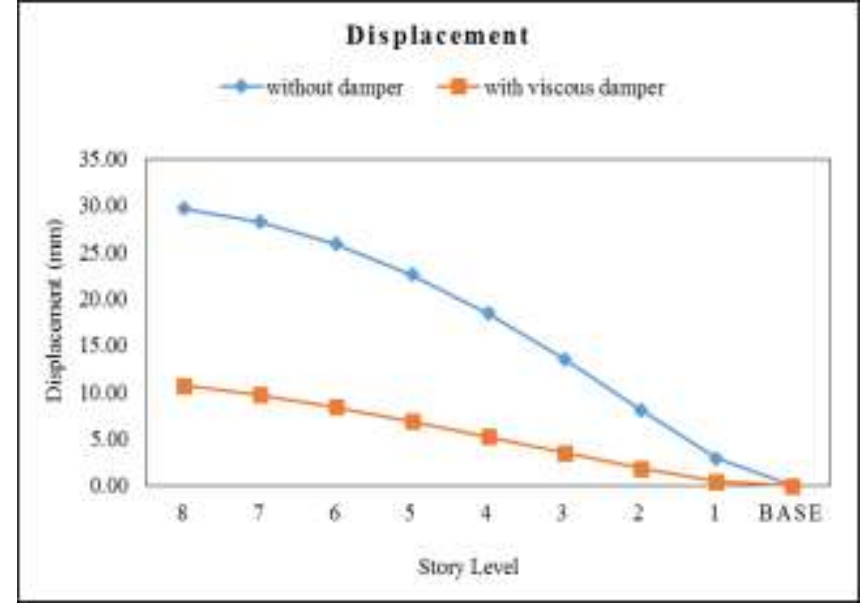

Fig 8: Comparison of Displacement

\subsection{Story Drift}

As the number of story increases in the structure, the drift is the common factor for multi-story building. The variance between the lateral displacements of two adjacent floors of the structure is defined as the story drift.

The structure which is modelled and analysed by dynamic analysis i.e., response spectrum method. The values of the story drift of the structure is noted for maximum load combination.

Table 3: Story Drift (mm)

\begin{tabular}{|c|c|c|c|}
\hline \multirow[b]{2}{*}{ Story } & \multirow{2}{*}{$\begin{array}{l}\text { Elevation } \\
\text { (m) }\end{array}$} & \multicolumn{2}{|c|}{ Story Drift (mm) } \\
\hline & & $\begin{array}{l}\text { without } \\
\text { damper }\end{array}$ & $\begin{array}{l}\text { with } \\
\text { viscous } \\
\text { damper }\end{array}$ \\
\hline 8 & 24 & 0.00059 & 0.00035 \\
\hline 7 & 21 & 0.00094 & 0.00045 \\
\hline 6 & 18 & 0.00125 & 0.00052 \\
\hline 5 & 15 & 0.00149 & 0.00056 \\
\hline 4 & 12 & 0.00168 & 0.00057 \\
\hline 3 & 9 & 0.00181 & 0.00055 \\
\hline 2 & 6 & 0.00174 & 0.00047 \\
\hline 1 & 3 & 0.00097 & 0.00015 \\
\hline Base & 0 & 0 & 0 \\
\hline
\end{tabular}

STORY DRIFT

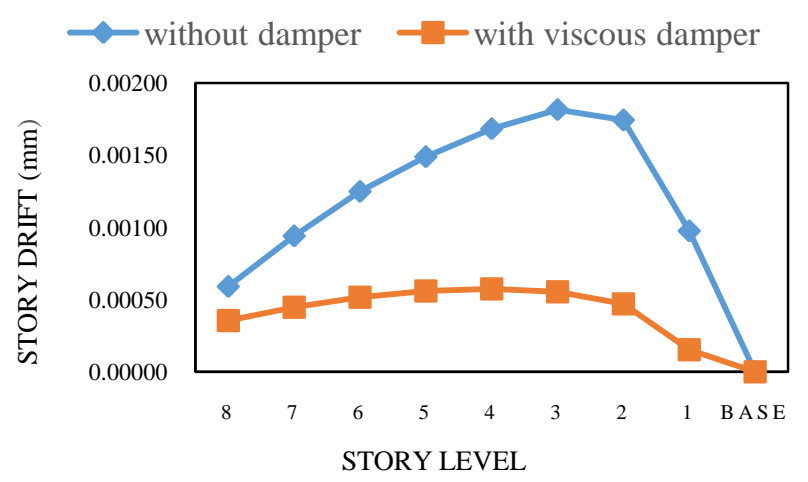

Fig 9: Comparison of Story Drift 


\subsection{Story Shear}

The story shear is the shear value obtained from the sum of design lateral forces at the levels above the story consideration of the structure. The story shear at bottom stories will be maximum and will be minimum at the top stories. The shear values of the both models are below in the table.

Table 4: Story Shear $(\mathrm{kN})$

\begin{tabular}{|l|l|l|l|}
\hline \multirow{2}{*}{ Story } & \multirow{2}{*}{$\begin{array}{l}\text { Elevation } \\
(\mathbf{m})\end{array}$} & $\begin{array}{l}|l| \\
\text { Sithout } \\
\text { damper }\end{array}$ & $\begin{array}{l}\text { Story Shear } \\
\text { with } \\
\text { viscous } \\
\text { damper }\end{array}$ \\
\cline { 3 - 4 } & & 288.26 & 293.36 \\
\hline 8 & 24 & 571.35 & 623.03 \\
\hline 7 & 21 & 758.14 & 881.01 \\
\hline 6 & 18 & 891.75 & 1088.39 \\
\hline 5 & 15 & 1007.25 & 1254.22 \\
\hline 4 & 12 & 1124.19 & 1381.26 \\
\hline 3 & 9 & 1232.17 & 1463.58 \\
\hline 2 & 6 & 1291.18 & 1487.82 \\
\hline 1 & 3 & 0 & 0 \\
\hline Base & 0 & & \\
\hline
\end{tabular}

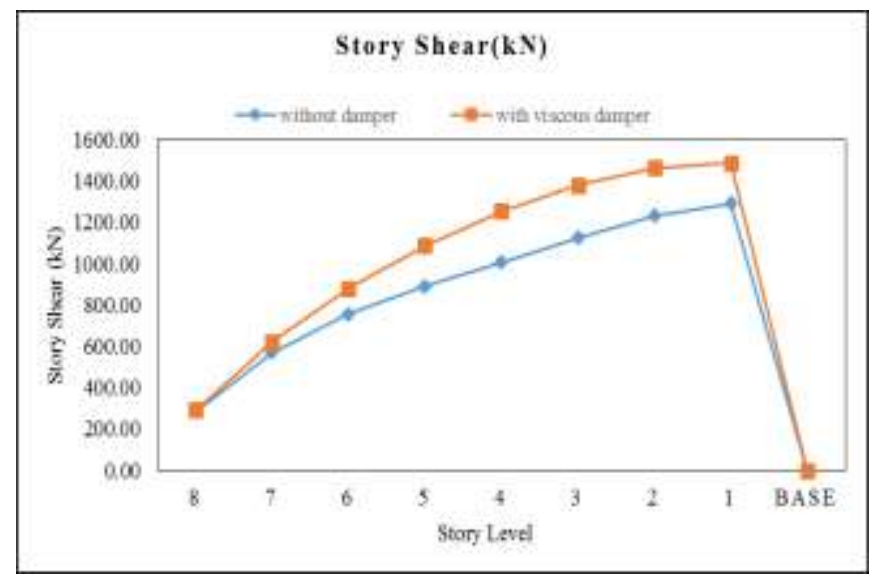

Fig 10: Comparison of Story Shear

\section{CONCLUSION}

In this study, viscous damper is used to control the seismic response of the structure which is subjected to the earthquake load. The symmetrical plan of 8 -stories is modelled and subjected to the class of gravity load using ETABs 2015. As per IS 1893-2002 code, the structure is subjected to the earthquake load. The response spectrum method is used for dynamic analysis. After analysing the structure and considering the static and dynamic values the scale factor is fixed. After the analyses of structure the results obtained and compared. And the conclusion are as follows,

1. According to the obtained results, viscous damper in structure results in the decrease of building displacement and building drift.
2. The bare frame model which is without damper is analysed and obtained the results of displacement as $29.63 \mathrm{~mm}$ and story drift as $0.00181 \mathrm{~mm}$.

3. The results obtained from the model with addition of viscous damper are displacement as $10.73 \mathrm{~mm}$ and story drift as $0.00055 \mathrm{~mm}$.

4. By observing, the displacement values increases over the height of the structure.

5. From the comparison, the displacement value of the structure is reduced about $60 \%$ to $85 \%$ when viscous dampers are applied to the structure.

6. With the placement of viscous damper into the structure maximum drift reduces in the structure during seismic loading.

7. By using viscous damper in the structure, the story drift at mid-stories is reduced by $70 \%$ when compared with bare model.

8. By applying viscous damper to the structure there is reduction of about $60 \%$ to $80 \%$ in drift value at top and bottom stories.

9. The base shear value of bare frame model is 1291.18 $\mathrm{kN}$ and that to model with viscous damper is 1487.82 $\mathrm{kN}$.

10. By observing the shear value, the difference is less because of the weight of the damper provided to the structure.

11. From the study, by applying viscous dampers to the structure its behaviour change under seismic loading.

12. . By observing, these viscous damper devices perform a vital role in reducing and controlling the seismic response of the structure.

\section{REFERENCES}

[1] Vajreshwari Umachagi, Katta Venkataramana, G. R. Reddy, Rajeev Verma, "Applications of Dampers for Vibration Control Of Structures: An Overview" International Journal of Research in Engineering and Technology, Nov-2013.

[2] Liya Mathew \& C. Prabha, "Effect of Fluid Viscous Dampers in Multi-Storeyed Buildings", International Journal of Research in Engineering \& Technology, Vol. 2, Issue 9, Sep 2014, 55-60.

[3] Su Myat Aye, Dr. Kyaw Moe Aung, "Comparative Study on Seismic Response of RC Structure Using Viscous Dampers and Viscoelastic Dampers", International Journal Of Scientific Engineering And Technology Research, Vol.03, Issue.08, May-2014, Pages:1468-1478.

[4] Mohammad Javad Dehghan, Mostafa Soleymannejad, "Improving Seismic Performance of Concrete Buildings with Special Moment Frames Using Viscous Damper", International Journal of Modern Engineering Research, Vol. 5, Issue. 7, July 2015.

[5] Yuvraj Bisht, Saraswati Setia, "Seismic Behaviour Of A Soft Storey Building With \& Without Viscous Dampers", International Journal of Engineering Research and Applications (IJERA) ISSN: 2248-9622, pg. no $10-15$

[6] V. Sadeghi Balkanlou, M. Reza Bagerzadeh Karimi, B. Bagheri Azar And Alaeddin Behravesh, "Evaluating 
Effects of Viscous Dampers on optimizing Seismic Behaviour of Structures", International Journal of Current Engineering and Technology, Vol.3, No.4 (October 2013), pg.no 1150-1157.

[7] Douglas Taylor, President, Taylor Devices Inc., "History, Design and Application of Fluid Dampers in Structural engineering"

[8] Godhat Kishan J. and Yashwantsinh Zala, "A Review on Effect of Actual Site Specific Response Analysis of Tall Building with Viscous Damper", International Journal of Trend in Research and Development, Volume 2(6), Nov - Dec 2015, pg.no.298-302.

[9] Lee. D., and Taylor. D. P, "Viscous damper development and future trends", Struct. Des. Tall Build, vol-10(5), 2001, pg.no-(311-320).

[10] Alireza Heysami, "Types of Dampers and their Seismic Performance during an Earthquake", Current World Environment, Vol. 10(Special Issue 1), 1002-1015 (2015).

[11] Dharmesh Chandnani, Riddhi Joshi, Kumarpal Trivedi, "Characteristics \& Applications of Different Types of Dampers as Seismic Energy Dissipater", International Journal of Computer Science and Network, Volume 5, Issue 2, April 2016 pg.no (369-372). 